\title{
Experimental determination of layer cloud edge charging from cosmic ray ionisation
}

Article

Published Version

Nicoll, K. A. and Harrison, R. G. (2010) Experimental determination of layer cloud edge charging from cosmic ray ionisation. Geophysical Research Letters, 37 (13). L13802. ISSN 0094-8276 doi: https://doi.org/10.1029/2010GL043605 Available at https://centaur.reading.ac.uk/16408/

It is advisable to refer to the publisher's version if you intend to cite from the work. See Guidance on citing.

Published version at: http://dx.doi.org/10.1029/2010GL043605

To link to this article DOI: http://dx.doi.org/10.1029/2010GL043605

Publisher: American Geophysical Union

All outputs in CentAUR are protected by Intellectual Property Rights law, including copyright law. Copyright and IPR is retained by the creators or other copyright holders. Terms and conditions for use of this material are defined in the End User Agreement.

\section{www.reading.ac.uk/centaur}

\section{CentAUR}

Central Archive at the University of Reading

Reading's research outputs online 


\title{
Experimental determination of layer cloud edge charging from cosmic ray ionisation
}

\author{
K. A. Nicoll ${ }^{1}$ and R. G. Harrison ${ }^{1}$ \\ Received 13 April 2010; revised 20 May 2010; accepted 26 May 2010; published 2 July 2010.
}

[1] The cloud-air transition zone at stratiform cloud edges is an electrically active region where droplet charging has been predicted. Cloud edge droplet charging is expected from vertical flow of cosmic ray generated atmospheric ions in the global electric circuit. Experimental confirmation of stratiform cloud edge electrification is presented here, through charge and droplet measurements made within an extensive layer of supercooled stratiform cloud, using a specially designed electrostatic sensor. Negative space charge up to $35 \mathrm{pC} \mathrm{m}^{-3}$ was found in a thin $(<100 \mathrm{~m})$ layer at the lower cloud boundary associated with the clear air-cloud conductivity gradient, agreeing closely with space charge predicted from the measured droplet concentration using ion-aerosol theory. Such charge levels carried by droplets are sufficient to influence collision processes between cloud droplets. Citation: Nicoll, K. A., and R. G. Harrison (2010), Experimental determination of layer cloud edge charging from cosmic ray ionisation, Geophys. Res. Lett., 37, L13802, doi:10.1029/2010GL043605.

\section{Introduction}

[2] Ionisation from galactic cosmic rays is the main source of atmospheric cluster ion production away from the Earth's surface. Ions move vertically due to the substantial potential difference $(250 \mathrm{kV})$ between the Earth's surface and the ionosphere, creating a small ion current density, $\mathrm{J}_{\mathrm{c}}$. Theory suggests that vertical ion current flow through extensive layers of stratiform cloud will cause accumulation of space charge on the upper and lower cloud edges, with charge transferred to cloud droplets and aerosol particles in these regions [Tinsley, 2000]. Cloud microphysical processes such as droplet-droplet collisions [Khain et al., 2004], droplet-particle collisions [Tinsley et al., 2000; Tripathi and Harrison, 2002] and droplet formation [Harrison and Ambaum, 2008], are influenced by charge. In turn these may affect cloud droplet size distributions, precipitation, cloud lifetime, and cloud radiative properties.

[3] Many observations of droplet cloud charge have been made within thunderstorms, but fewer measurements of cloud droplet charge in stratiform clouds exist. Pruppacher and Klett [1998] review previous stratiform cloud droplet measurements, mostly made at mountaintop observatories [e.g., Twomey, 1956; Phillips and Kinzer, 1958; Allee and Phillips, 1959]. Phillips and Kinzer [1958] found cloud droplet charges between $-20 e$ and $20 e$ in stratocumulus, but the measurement position relative to the cloud boundaries

\footnotetext{
${ }^{1}$ Department of Meteorology, University of Reading, Reading, UK.
}

Copyright 2010 by the American Geophysical Union. 0094-8276/10/2010GL043605 was not reported. Furthermore, droplet charges inside mountaintop clouds may not be representative of the cloud electrical environment well above the surface [Beard et al., 2004]. Airborne measurements of droplet charges in altostratus cloud [Beard et al., 2004] support theoretical expectations of negative charges around cloud base and positive charges at cloud top, however these measurements were made around the middle of the cloud rather than at the edges where the charge is thought to originate. Measurements of charge actually on the cloud edges are therefore required for more robust confirmation of stratiform cloud edge charging.

[4] This work presents experimental confirmation of charge accumulation on the edges of layer clouds, from in-situ measurements of charge and cloud droplets within an extensive layer of stratiform cloud over the southern UK, using a balloon platform.

\section{Meteorological Circumstances and Measurement Details}

[5] In-situ cloud measurements were made by a sensitive balloon-carried Cloud Edge Charge Detector (CECD) [Nicoll and Harrison, 2009a], and a wing-mounted Cloud Droplet Probe (CDP) carried by the Facility for Airborne Atmospheric Measurement (FAAM) BAe 146 aircraft. The CDP measured droplets with diameters from 1-50 $\mu \mathrm{m}$, and both instruments also recorded temperature and their GPS position. Both instruments sampled an extensive stratocumulus cloud present over the southern UK on $18 / 02 / 09$, associated with a weak weather front. Within this feature, two cloud layers were present, a lower layer with cloud top $\sim 1.5 \mathrm{~km}$ and a uniform upper supercooled (temperature $<0^{\circ} \mathrm{C}$ ) layer, with cloud top $\sim 3.7 \mathrm{~km}$. The upper cloud layer is considered further here, which is apparent on the infrared satellite image from 1400 UTC on 18/02/09 (Figure 1a) as the cloud band.

[6] The radiosonde carrying the charge sensor was released from Reading at 1330 UTC $\left(51.45^{\circ} \mathrm{N}, 0.97^{\circ} \mathrm{W}\right)$, and travelled south before descending by parachute over Portsmouth $\left(50.80^{\circ} \mathrm{N}, 1.05^{\circ} \mathrm{W}\right)$, passing through the upper cloud layer at 1520 UTC. This upper cloud layer was also sampled by the FAAM aircraft at 1200 UTC, over Yeovil $\left(50.95^{\circ} \mathrm{N}, 2.63^{\circ} \mathrm{W}\right)$. The slightly earlier sampling by the aircraft, combined with the easterly progression of the weather front and the longevity of the cloud conditions suggests that cloud droplet properties encountered by the CDP and CECD were similar, despite the horizontal separation of $\sim 120 \mathrm{~km}$. Further evidence for the upper cloud layer's uniformity is apparent in the similar atmospheric temperature profiles (Figure 1b), measured by the CECD radiosonde, the FAAM aircraft and the lower vertical resolution standard midday meteorological soundings from 
(a)

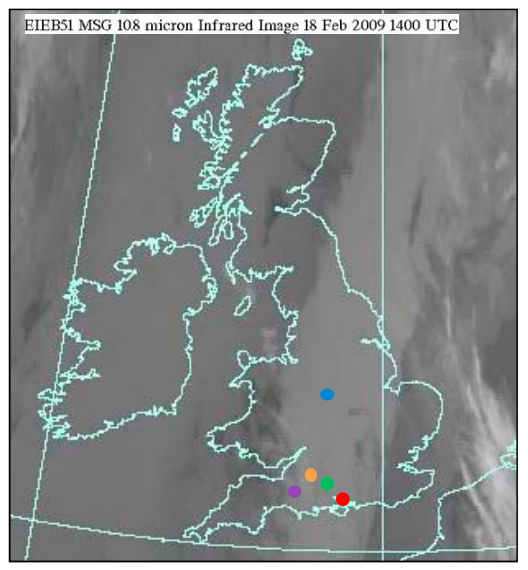

(b)

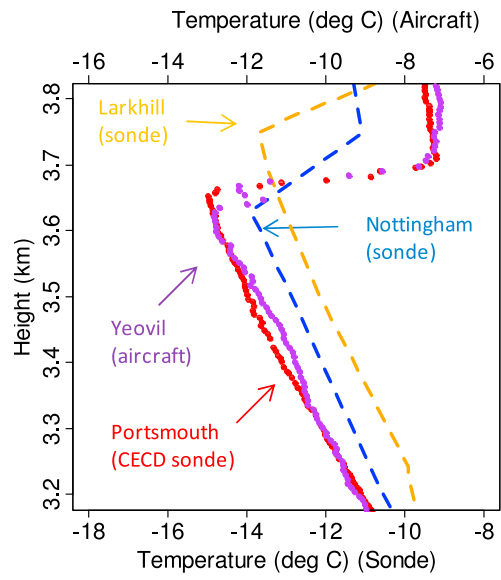

Figure 1. (a) Infrared satellite image (C) British Crown copyright [2009] the Met Office, showing cloud cover over the UK at 1400 UTC on 18/02/09 with lower (dark grey) and upper (light grey) stratocumulus layers. The red circle denotes the position of the CECD radiosonde passing through the upper cloud layer (at 1520 UTC), the purple circle represents the position of the CDP on the FAAM aircraft when it passed through the upper cloud layer (1200 UTC), and the green circle the Chilbolton radar. Orange and blue circles mark Larkhill and Nottingham respectively. (b) Temperature profiles surrounding the upper cloud layer. Lower x-axis: red, CECD radiosonde (1520 UTC); orange, Larkhill radiosonde (1200 UTC); blue, Nottingham radiosonde (1200 UTC). Upper x-axis: purple, FAAM aircraft (1200 UTC). The top of the cloud layer is shown by the temperature inversion at $3.7 \mathrm{~km}$.

Nottingham $\left(52.95^{\circ} \mathrm{N}, 1.15^{\circ} \mathrm{W}\right)$ and Larkhill $\left(51.20^{\circ} \mathrm{N}\right.$, $\left.1.81^{\circ} \mathrm{W}\right)$. Figure $1 \mathrm{~b}$ demonstrates that the atmospheric thermal structure and the associated cloud top height (as given by the temperature inversion height at $\sim 3.65 \mathrm{~km}$ ) was comparable despite the different times and locations of measurements. In addition, remote sounding data available from the $35 \mathrm{GHz}$ cloud radar at Chilbolton Observatory $\left(51.14^{\circ} \mathrm{N}, 1.44^{\circ} \mathrm{W}\right)$, also beneath the persistent cloud layer, showed the same cloud structure from 0900 UTC to 1800 UTC.

[7] Near cloud, the charge sensor operates by induction, generating a voltage of opposite polarity to the nearby charge, in a $12 \mathrm{~mm}$ diameter insulated spherical electrode. The voltage change is proportional to the amount of charge and rate of vertical motion. Quantitative space charge can be derived from the rate of change of electrode voltage [Nicoll and Harrison, 2009a], $V$, as

$$
\rho=-\frac{\varepsilon_{0}}{r_{e f f}} \frac{1}{w} \frac{d V}{d t},
$$

where $w$ is the vertical speed and $r_{\text {eff }}$ the effective electrode radius, found by laboratory calibration [Nicoll, 2010]. $w$ (typically $4 \mathrm{~ms}^{-1}$ during ascent and descent) was found from successive pressure measurements, each yielding the height. Both differential quantities $d V / d t$ and $w$ were calculated by fitting local smoothing splines to the raw data, which was sampled at $1 \mathrm{~Hz}$.

[8] Cloud droplet properties measured by the FAAM aircraft's CDP are given in Figure 2a showing the cloud base at $\sim 3.3 \mathrm{~km}$ and in-cloud cloud droplet number concentration $\sim 50 \mathrm{~cm}^{-3}$, with the usual reduction in size and concentration towards the cloud edge. An interpolation spline has been added to provide a smoothed profile and permit calculations based on the droplet measurements. Figure $2 b$ shows the associated variation in CECD electrode voltage as it descended through the cloud layer. The electrode was initially at negative saturation (induced from local positive charge) as it reached and entered the upper cloud edge: the sensor saturation prevented the upper cloud edge charge being measured. On emerging from the cloud base the electrode voltage increased, mirroring the droplet concentration change recorded by the aircraft's CDP. Because of the charge sensor's operation by induction, the observed positive increase in voltage in Figure $2 \mathrm{~b}$ below $3.4 \mathrm{~km}$ indicates negative charge on the lower cloud edge.

\section{Cloud Edge Space Charge}

[9] Space charge occurs on stratiform cloud edges because of vertical ion current flow through the vertical air conductivity gradient caused by the cloud [Zhou and Tinsley, 2007]. The vertical air conductivity gradient arises from the transition between droplet-free air in which cluster ions formed by cosmic rays are removed only by their selfrecombination, to that of the droplet-laden cloud, where the ion concentration is greatly depleted by attachment to droplets. Cloud edge electrification clearly also requires the ion current density $J_{\mathrm{c}}$ to pass continuously through the droplet region, which has been demonstrated to occur with extensive cloud [Nicoll and Harrison, 2009b] and fog layers [Bennett and Harrison, 2009].

[10] The vertical gradient in conductivity at a cloud edge creates a vertical gradient in the electric field $E_{z}$ in the same region. Gauss's law of electrostatics relates a vertical electric field gradient $d E_{z} / d z$ to space charge density $\rho$ by

$$
\frac{d E_{z}}{d z}=-\frac{\rho}{\varepsilon_{0}},
$$

where $\varepsilon_{0}$ is the permittivity of free space, yielding positive charge at a layer cloud top and negative charge at the bottom. Assuming Ohm's law $\left(J_{c}=\sigma E\right.$, for air conductivity $\left.\sigma\right)$, the 
(a)

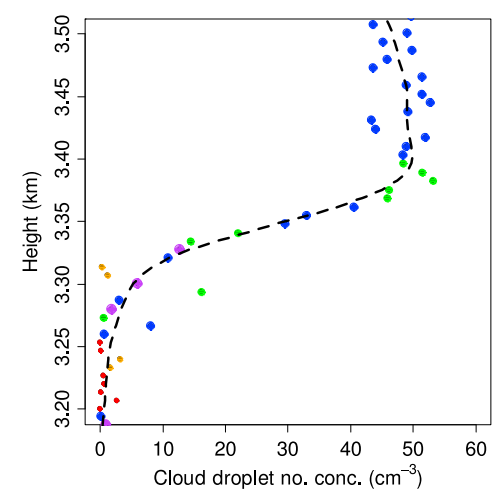

(c)

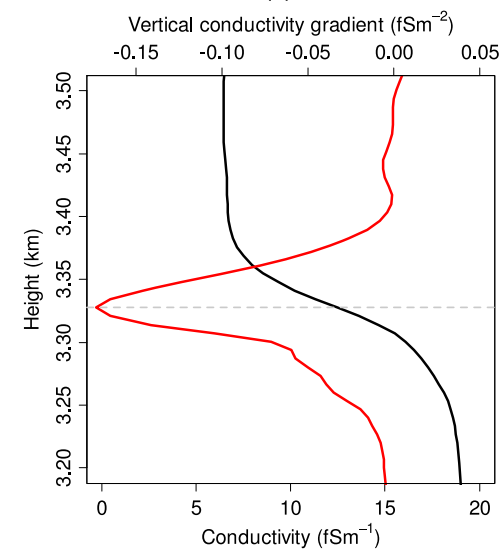

(b)

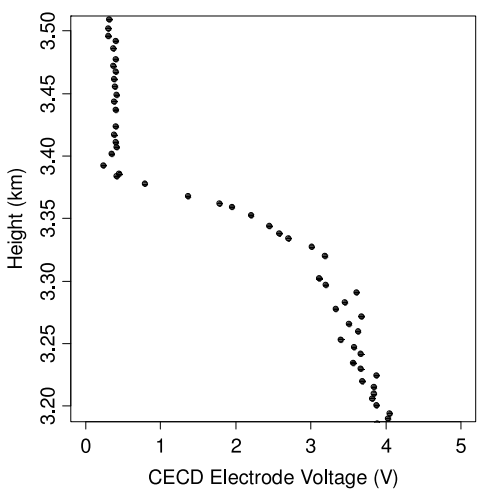

(d)

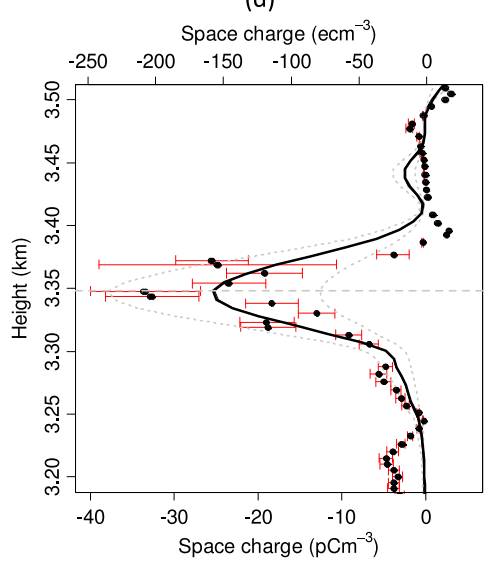

Figure 2. (a) Vertical profile of cloud droplet number concentration measured by the CDP on the FAAM aircraft on $18 / 02 / 09$, coloured by droplet diameter $d$ (red represents $d<5 \mu \mathrm{m}$, orange $5 \mu \mathrm{m}<d<10 \mu \mathrm{m}$, green $10 \mu \mathrm{m}<d<15 \mu \mathrm{m}$, blue $15 \mu \mathrm{m}<d<$ $20 \mu \mathrm{m}$, and purple $d>20 \mu \mathrm{m}$ ), with an interpolating spline applied (dashed line). (b) CECD electrode voltage measured on radiosonde descent through the same cloud layer. (c) Calculated air conductivity (black solid line) and its vertical gradient (red solid line), with altitude of maximum gradient marked (grey dashed line). (External aerosol properties assumed: concentration $Z=1000 \mathrm{~cm}^{-3}$ and radius $a=0.2 \mu \mathrm{m}$ ). (d) Measured (black points) and calculated (solid line) cloud space charge using equation (3) and $J_{c}=2 \mathrm{pA} \mathrm{m}^{-2}$, including the range of values varying $J_{\mathrm{c}}$ to $=1 \mathrm{pA} \mathrm{m}^{-2}$ and $3 \mathrm{pA} \mathrm{m} \mathrm{m}^{-2}$ (grey dotted lines). The altitude of the space charge maximum is marked by the horizontal grey dashed line.

space charge density can be written in terms of constant vertical current density $J_{c}$, as

$$
\rho=-\varepsilon_{0} J_{c} \frac{d}{d z}\left(\frac{1}{\sigma}\right)=+\varepsilon_{0} J_{c}\left(\frac{1}{\sigma^{2}}\right) \frac{d \sigma}{d z} .
$$

Equation (3) permits calculation of the cloud edge space charge, for a known conductivity profile at the cloud edge. This can be found from the cloud droplet number concentration, using the steady-state ion balance equation [e.g., Harrison and Carslaw, 2003], assuming the total conductivity is given by the mean ion concentration as

$$
\sigma=\frac{\mu e}{\alpha}\left(\sqrt{\left(\beta^{2} Z^{2}+\beta_{d}^{2} Z_{d}^{2}+4 \alpha q\right)}-\left(\beta Z+\beta_{d} Z_{d}\right)\right),
$$

where $\mu$ is the ion mobility, $e$ the elementary charge, $\alpha$ the ion-ion recombination coefficient, $Z$ the background monodisperse aerosol number concentration, $Z_{\mathrm{d}}$ the monodisperse droplet number concentration, and $\beta$ and $\beta_{\mathrm{d}}$ the size-dependent ion-aerosol and ion-droplet attachment coefficients. Figure $2 \mathrm{a}$ shows the CDP measurements of $Z_{\mathrm{d}}$ near the cloud base. Using the interpolation spline fitted to the measured $Z_{\mathrm{d}}$ data, the vertical conductivity profile has been calculated from equation (4), assuming $\mu=1.7 \times$ $10^{-4} \mathrm{~m}^{2} \mathrm{~V}^{-1} \mathrm{~s}^{-1}$ and $\alpha=1.6 \times 10^{-12} \mathrm{~m}^{3} \mathrm{~s}^{-1}$, using attachment coefficients [Gunn, 1954] calculated for the approximation of neutral droplets [Harrison and Ambaum, 2008]. The vertical profile of calculated conductivity is shown in Figure $2 \mathrm{c}$ in black.

[11] The ion production rate $q$ from cosmic rays varies with the solar cycle, but the southern UK measurement [Harrison, 2005] of $q=4 \mathrm{~cm}^{-3} \mathrm{~s}^{-1}$ at $3.3 \mathrm{~km}$ assumed in the calculation of the conductivity agrees with the model predictions of Usoskin and Kovalstov [2006]. In equation (4), the aerosol external to the cloud is assumed to have concentration $\mathrm{Z}=1000 \mathrm{~cm}^{-3}$ and radius $0.2 \mu \mathrm{m}$ [Pruppacher and Klett, 1998], but, as these parameters serve only to define the clear air conductivity, they do not strongly affect the rate of change of conductivity which is dominated by the measured droplet properties. From Figure 2c, the calculated conductivity decreases as the cloud droplet concentration increases, becoming constant inside the cloud. The derived 


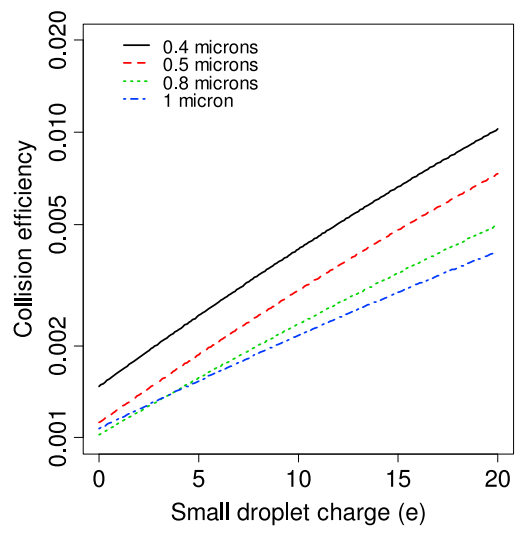

Figure 3. Collision efficiency for a small charged droplet interacting with a large neutral droplet (small and large droplet densities $1 \mathrm{~g} \mathrm{~cm}^{-3}$, and large droplet radius $20 \mu \mathrm{m}$ ), as a function of small droplet charge, for small droplet radii of $0.4,0.5,0.8$ and $1.0 \mu \mathrm{m}$. Collision efficiency was calculated using the parameterisation of Tripathi et al. [2006].

vertical conductivity gradient is also shown in Figure $2 \mathrm{c}$ in red, which was used to calculate the space charge density using equation (3). The calculated space charge is shown in Figure $2 \mathrm{~d}$ as the black solid line. No ion conduction current density measurement was made during the sounding, but the median value at Reading for 2006 [Bennett, 2007], $J_{\mathrm{c}}=$ $2 \mathrm{pA} \mathrm{m}^{-2}$ is assumed to be representative. To allow for possible variations however, space charge values in Figure $2 \mathrm{~d}$ have also been calculated for $J_{c}=1 \mathrm{pA} \mathrm{m}^{-2}$ and $3 \mathrm{pA} \mathrm{m}^{-2}$ (grey dashed lines).

[12] Also shown in Figure 2d (as the black points), is the space charge measured by the CECD, derived directly from the sounding using equation (1). The uncertainty in the space charge shown in Figure $2 \mathrm{~d}$ was estimated by combining the fractional errors in $r_{\text {eff }}$ (using two standard errors on the mean $r_{\text {eff }}$ from eight calibration experiments), $w$, and $V$ (from the difference between CECD voltage measurements and the smoothed spline voltages, and assuming that the fractional error in $V \sim$ fractional error in $d V / d t$ ) [Nicoll, 2010]. A negative charge layer of $\sim 35 \mathrm{pC} \mathrm{m}^{-3}$ is apparent near the cloud base from the CECD observations, and is also predicted from the calculation based on the droplet measurements. The calculated and measured space charges agree closely in magnitude and location, indicating that the steady-state ion balance with the assumption of neutral droplets (which has a much smaller effect on the attachment coefficient than size) is reasonable. The data show that the charged layer is less than $100 \mathrm{~m}$ thick at the lower cloud edge, where both the cloud droplet sizes and concentrations are changing. The calculated maximum in the space charge (at $3348 \mathrm{~m}$ ) occurs at a slightly higher altitude than the calculated maximum in the conductivity gradient (at $3328 \mathrm{~m}$ ), as a result of the specific droplet concentration profile because of the combined effect of $1 / \sigma^{2}$ and $d \sigma / d z$ in equation (3). Charge is therefore associated with the droplet region of the cloud, rather than the expected haze layer beneath [e.g., Koren et al., 2007]. The measured space charge can equivalently be expressed as a mean droplet charge $j$ from $j=\rho / N e$, where $\rho$ is the space charge, $e$ the elementary charge and $N$ the cloud droplet number concentration. This assumes the charge is distributed evenly between droplets. Figure $2 \mathrm{~d}$ shows the maximum mean droplet charge at cloud base to be $17 e$, comparable to direct measurements made inside stratiform clouds [Beard et al., 2004].

[13] The horizontal separation between the cloud droplet and CECD measurements presents the possibility that the cloud droplet distributions may differ between the two sites, due to local aerosol particle variations. This appears unlikely as the maxima of the measured and calculated space charge in Figure $2 \mathrm{~d}$ occur at the same height, indicating that the droplet profile measured by the FAAM aircraft was similar to that encountered by the CECD. (If the droplet profiles were different, different conductivity gradient profiles would occur, generating different space charge profiles).

\section{Effect of Measured Charge on Cloud Droplet Interactions}

[14] Observations reported here confirm charging at layer cloud edges, thus to provide the physical context for the charge levels observed on 18/02/09, the effects of charge on the behaviour of cloud droplets is briefly investigated. Cloud droplet charging influences the forces acting between droplets, and therefore droplet-droplet interactions such as collisions. The collision efficiency is the fraction of all cloud drops in the path of a falling larger drop that make contact with the larger drop. Calculations of the collision efficiency between a small charged cloud droplet and a large neutral cloud droplet (radii fixed at $20 \mu \mathrm{m}$ ) have been made for various radii of small droplets possessing charges of similar magnitude to those observed on 18/02/09. The collision efficiency parameterization of Tripathi et al. [2006] was used, assuming unit density for both interacting particles. This assumes that, for large droplet charge $\ll 1000 e$, typical of stratiform clouds, the large droplet charge does not affect the collision efficiency. Collision efficiency is shown in Figure 3, as a function of small droplet charge for various sizes of droplet, demonstrating that the effect of electrification is most pronounced for droplets with small radii. For the smallest droplets, with radii $0.4 \mu \mathrm{m}$, the collision efficiency is 7 times greater when the droplet possesses a charge of $20 e$, compared to the neutral case. Charging of small droplets to less than $20 e$ may therefore facilitate their coalescence with larger droplets, by electrostatically enhancing the collision efficiency.

\section{Discussion}

[15] These results demonstrate a new high resolution measurement approach for cloud edge electrification studies. The cloud edge charge observed is sufficient to influence small cloud droplet (radius $<1 \mu \mathrm{m}$ ) collision efficiency by attractive electrostatic image forces. Layer clouds cover $\sim 40 \%$ of the planet [Klein and Hartmann, 1993], which suggests that layer cloud edge charging by the globally present vertical ion current may be common.

[16] Solar modulation of cosmic rays has been shown to influence the global circuit ion current [Markson and Muir, 1980; Harrison and Usoskin, 2010]. As this current causes the cloud edge charging reported here, some solar modulation of cloud edge charge may therefore be expected. This will vary with cloud height and location, due to the combined effect of solar modulation on both ion production and 
global circuit ion current. This is illustrated by equation (3), which shows that the change in cloud edge space charge depends on both the relative change in $d \sigma / d z$ and $J_{c}$, since increased ionization is likely to decrease $d \sigma / d z$, but increase $J_{\text {c. }}$ Near the continental surface up to $\sim 2 \mathrm{~km}$ height, radon ionization dominates over cosmic ray ionization, therefore for low altitude continental clouds, any solar modulation of global circuit current $J_{\mathrm{c}}$ would not be fully compensated by solar modulation of cosmic ray ion production. This suggests greater solar modulation of cloud edge charge in low clouds than high clouds, therefore these results provide experimental support for the hypothesis [Ney, 1959; Tinsley, 2000] of a cosmic ray link between the heliosphere and lower atmosphere cloud processes.

[17] Acknowledgments. The FAAM flight was funded by the NERC APPRAISE-CLOUD campaign, project NE/E011241/1, from which C. D. Westbrook provided the cloud droplet measurements. Figure 1a is from EUMETSAT (http://www.metoffice.gov.uk/satpics/latest_uk_ir.html), and the radiosonde data from the UK sites of Larkhill and Nottingham was provided by University of Wyoming (http://weather.uwyo.edu/upperair/ sounding.html). KAN was funded by the Natural Environment Research Council.

\section{References}

Allee, P. A., and B. B. Phillips (1959), Measurement of cloud-droplet charge, electric field and polar conductivities in supercooled clouds, J. Atmos. Sci., 16(4), 405-410, doi:10.1175/1520-0469(1959) 016<0405:MOCDCE $>2.0 . C O ; 2$.

Beard, K. V., H. T. Ochs III, and C. H. Twohy (2004), Aircraft measurements of high average charges on cloud drops in layer clouds, Geophys. Res. Lett., 31, L14111, doi:10.1029/2004GL020465.

Bennett, A. J. (2007), Measurement of atmospheric electricity during different meteorological conditions, Ph.D. thesis, Univ. of Reading, Reading, U. K.

Bennett, A. J., and R. G. Harrison (2009), Evidence for global circuit current flow through water droplet layers, J. Atmos. Sol. Terr. Phys., 71(12), 1219-1221, doi:10.1016/j.jastp.2009.04.011.

Gunn, R. (1954), Diffusion charging of atmospheric droplets by ions and the resulting combination coefficients, J. Meteorol., 11, 339-347.

Harrison, R. G. (2005), Meteorological radiosonde interface for atmospheric ion production rate measurements, Rev. Sci. Instrum., 76, 126111, doi:10.1063/1.2149005.

Harrison, R. G., and M. H. P. Ambaum (2008), Enhancement of cloud formation by droplet charging, Proc. R. Soc. A, 464, 2561-2573, doi:10.1098/rspa.2008.0009.

Harrison, R. G., and K. S. Carslaw (2003), Ion-aerosol-cloud processes in the lower atmosphere, Rev. Geophys., 41(3), 1012, doi:10.1029/ 2002RG000114.
Harrison, R. G., and I. Usoskin (2010), Solar modulation in surface atmospheric electricity, J. Atmos. Sol. Terr. Phys., 72(2-3), 176-182, doi:10.1016/j.jastp.2009.11.006.

Khain, A., M. Arkhipov, M. Pinsky, Y. Feldman, and Y. Ryabov (2004), Rain enhancement and fog elimination by seeding with charged droplets. Part 1: Theory and numerical simulations, J. Appl. Meteorol., 43, 15131529, doi:10.1175/JAM2131.1.

Klein, S. A., and D. L. Hartmann (1993), The seasonal cycle of low stratiform clouds, J. Clim., 6, 1587-1606, doi:10.1175/1520-0442(1993) $006<1587$ :TSCOLS $>2.0$. CO 2 .

Koren, I., L. A. Remer, Y. J. Kaufman, Y. Rudich, and J. Vanderlei Martins (2007), On the twilight zone between clouds and aerosols, Geophys. Res. Lett., 34, L08805, doi:10.1029/2007GL029253.

Markson, R., and M. Muir (1980), Solar wind control of the Earth's electric field, Science, 208(4447), 979-990, doi:10.1126/science.208.4447.979.

Ney, E. P. (1959), Cosmic radiation and the weather, Nature, 183, 451-452, doi:10.1038/183451a0.

Nicoll, K. A. (2010), Coupling between the Global Atmospheric Electric Circuit and Clouds, Ph.D. thesis, Univ. of Reading, Reading, U. K.

Nicoll, K. A., and R. G. Harrison (2009a), A lightweight balloon-carried cloud charge sensor, Rev. Sci. Instrum., 80, 014501, doi:10.1063/ 1.3065090 .

Nicoll, K. A., and R. G. Harrison (2009b), Vertical current flow through extensive layer clouds, J. Atmos. Sol. Terr. Phys., 71(17-18), 2040-2046, doi:10.1016/j.jastp.2009.09.011.

Phillips, B. B., and G. D. Kinzer (1958), Measurements of the size and electrification of droplets in cumuliform clouds, J. Meteorol., 15, 369-374.

Pruppacher, H. R., and J. D. Klett (1998), Microphysics of Cloud and Precipitation, Kluwer Acad., Dordrecht, Netherlands.

Tinsley, B. A. (2000), Influence of solar wind on the global electric circuit, and inferred effects on cloud microphysics, temperature, and dynamics in the troposphere, Space Sci. Rev., 94(1-2), 231-258, doi:10.1023/ A:1026775408875.

Tinsley, B. A., R. P. Rohrbauch, M. Hei, and K. V. Beard (2000), Effects of image charges on the scavenging of aerosol particles by cloud droplets and on droplet charging and possible ice nucleation processes, J. Atmos. Sci., 57, 2118-2134, doi:10.1175/1520-0469(2000)057<2118:EOICOT> 2.0.CO;2.

Tripathi, S. N., and R. G. Harrison (2002), Enhancement of contact nucleation by scavenging of charged aerosol particles, Atmos. Res., 62(1-2), 57-70, doi:10.1016/S0169-8095(02)00020-0.

Tripathi, S. N., S. Vishnoi, S. Kumar, and R. G. Harrison (2006), Computationally efficient expressions for the collision efficiency between electrically charged aerosol particles and cloud droplets, $Q$. J. R. Meteorol. Soc., 132, 1717-1731, doi:10.1256/qj.05.125.

Twomey, S. (1956), The electrification of individual cloud droplets, Tellus, 8, 445-452, doi:10.1111/j.2153-3490.1956.tb01247.x.

Usoskin, I. G., and G. A. Kovalstov (2006), Cosmic ray induced ionization in the atmosphere: Full modelling and practical applications, J. Geophys. Res., 111, D21206, doi:10.1029/2006JD007150.

Zhou, L., and B. A. Tinsley (2007), Production of space charge at the boundaries of layer clouds, J. Geophys. Res., 112, D11203, doi:10.1029/2006JD007998.

R. G. Harrison and K. A. Nicoll, Department of Meteorology, University of Reading, PO Box 243, Earley Gate, Reading RG6 6BB, UK. (k.a. nicoll@reading.ac.uk) 